\title{
Recent Work in the Epistemology of Understanding
}

\author{
Michael Hannon \\ University of Nottingham
}

\begin{abstract}
The philosophical interest in the nature, value, and varieties of human understanding has swelled in recent years. This article will provide an overview of new research in the epistemology of understanding, with a particular focus on the following questions: What is understanding and why should we care about it? Is understanding reducible to knowledge? Does it require truth, belief, or justification? Can there be lucky understanding? Does it require 'grasping' or some kind of 'knowhow'? This cluster of questions has largely set the research agenda for the study of understanding in epistemology. This article will conclude by discussing some varieties of understanding and highlight directions for future research.
\end{abstract}

Humans are naturally inquisitive creatures. As Aristotle observed, "All men by nature desire to know." But knowledge is not the only intellectual achievement at which humans aim, and it might not be the most valuable. As Albert Einstein once said, "Any fool can know; the point is to understand."

It is widely assumed that understanding is a valuable intellectual achievement; however, the cognitive state of understanding is itself poorly understood. What is understanding? Why is it valuable? And how do we achieve it? These questions are at the forefront of recent work in the epistemology of understanding. In this article, I will attempt to give a sense of the range and depth of this new research on the nature, value, and varieties of human understanding. I will also critically evaluate some of this work.

\footnotetext{
${ }^{1}$ The Aristotle quote is from the opening line of his Metaphysics. The Einstein quote can be found in Christian (1990, p. 207).
} 


\section{Understanding in Epistemology}

The philosophical interest in understanding has swelled in recent years. In epistemology, scholars have attempted to explore the nature, value, and varieties of understanding largely by comparison with knowledge. This methodology isn't surprising. Knowledge has been a focal point of modern epistemology, and the language of "knowing" is closely related to the language of "understanding." For example, "knows" and "understands" come in the same linguistic forms: just as one can know-that, know-how, know-who, know-what, know-where, know-when, and know-why, one can also understandthat, understand-how, understand-who, and so forth (Kvanvig 2009, p. 96). Moreover, the terms "knows" and "understands" are sometimes interchangeable; for instance, "I know that two plus two equals four" seems to express the same thought as "I understand that two plus two equals four" (Hannon 2019, p. 223). Knowing and understanding thus seem like closely related cognitive achievements. According to some scholars, the contrast between knowing and understanding is superficial (see Brogaard 2005).

However, ordinary parlance also points to some important differences between knowing and understanding. For example, Einstein's abovementioned remark implies that understanding is a much greater cognitive achievement than mere knowing. Duncan Pritchard echoes this idea: "We would surely rather understand than merely know" (2010, p. 74). Knowledge and understanding are often contrasted in a way that indicates that understanding may require a level of intellectual sophistication that is not necessarily demanded by knowledge. We find additional support for this idea by looking at other languages. As Alison Hills (2016, pp. 668-9) reports, many languages draw a similar distinction between knowing and understanding, including French:

Je sais que... I know that ...

Je comprends que ... I understand that ...

Je sais pourquoi... I know why...

Je comprends pourquoi... I understand why...

and German

Ich weiss dass... I know that...

Ich verstehe dass... I understand that... 
Ich weiss, warum... I know why ...

Ich verstehe, warum... I understand why ...

The distinction between knowing and understanding can also be found in Russian, Hebrew, Danish, and Irish, amongst others languages (Hills 2016, p. 668).

This linguistic data gives some prima facie support to the idea that knowing and understanding are distinct states. Presumably we wouldn't find this distinction in many natural languages if knowledge and understanding were simply interchangeable or referred to the same concept. This linguistic evidence is not conclusive, but it is suggestive.

The comparison between understanding and knowledge has led philosophers to concentrate their analyses on the following set of questions: Is understanding reducible to knowledge? Does it require truth? Can there be lucky understanding? Is it transmittable via testimony? Is it transparent in the sense that we know when we have achieved it? This cluster of questions has largely set the research agenda for the study of understanding in epistemology. Philosophers have sought to improve our understanding of understanding by comparing it with what we know about knowledge.

Let's start with the question whether understanding is reducible to knowledge. This is one of the most pressing questions in the epistemology of understanding because the reducibility of understanding to knowledge would suggest that we do not need separate accounts of these epistemic goods. Also, if understanding were simply a type of knowledge, then it would make little sense to say that understanding should replace knowledge as the primary focus of epistemology (e.g., Zagzebski 2001; Kvanvig 2003; Elgin 2006; Pritchard 2010). If, however, understanding were not reducible to knowledge, then this would threaten the justification for the focus on knowledge displayed in the history of epistemology. Indeed, "epistemology" is typically defined as the "theory of knowledge," and talk of knowledge has dominated the bulk of modern literature in epistemology. Thus, if understanding has a special status or value that knowledge does not, then philosophers may be accused of myopically focusing their efforts on analyzing knowledge at the expense of greater intellectual goods. 


\section{Is Understanding a Kind of Knowledge?}

Understanding, like knowledge, is an intellectual achievement. It is therefore unsurprising that, on many accounts, understanding is just a type of knowledge. This has been the dominant view in the philosophy of science and it is also popular within epistemology. Aristotle is perhaps the most prominent defender of this view (Posterior Analytics 71b9-11). He maintained that understanding is simply knowledge of causes. More specifically, understanding why $X$ is the case is equivalent to knowing why $X$ is the case; and this, in turn, is equivalent to knowing that $\mathrm{X}$ because of $\mathrm{Y}$. For example, my understanding of why my eyes are watering is equivalent to my knowing why my eyes are watering, where this is tantamount to knowing that my eyes are watering because (say) I am chopping onions.

In the philosophy of science, the view that understanding is just a type of knowledge has been defended by Peter Achinstein (1983), Wesley Salmon (1984), James Woodward (2003), Peter Lipton (2004, 2009), Kareem Khalifa (2011, 2012, 2017), and Mark Newman (2017). In epistemology, it has been taken up by Berit Brogaard (2005), Stephen Grimm (2006, 2012, 2014), John Greco (2014), Christoph Kelp (2014, 2015, 2017), Paulina Sliwa (2015), and Amber Riaz (2015), among others. For simplicity, I will use the label "reductionism" for the view that understanding is a species of knowledge.

Others have opposed the reduction of understanding to knowledge. According to these "antireductionists," understanding demands more than knowledge. Defenders of this view include Linda Zagzebski (2001), Jonathan Kvanvig (2003), Catherine Elgin (2004, 2007, 2009, 2017), Duncan Pritchard (2009, 2010), Alison Hills (2016), Wayne Riggs (2009), Christoph Baumberger (2011), Mikael Janvid (2012), Kevin Morris (2012), Yasha Rohwer (2014), Henk de Regt (2015, 2017), Sabine Ammon (2016), Insa Lawler (2016), Daniel Wilkenfeld (2017), and Finnur Dellsén (2017). These anti-reductionists have denied the reducibility of understanding to knowledge on various grounds, which I will explore in a moment. Let's first consider the reasons in favor of reductionism.

Why think that understanding is just a form of knowledge? On several accounts, it is because the conditions for understanding closely resemble the well-known traditional conditions of knowledge: belief, justification, and truth (Gettier 1963). As Baumberger and colleagues observe, understanding seems to require individuals to "possess a representation of what is understood," and it is plausible that "the representation must in some way be accepted by the agent" (Baumberger et al. 2017, p. 6). Thus, 
we end up with a condition that parallels the belief condition for knowledge. Moreover, it seems natural to say that one lacks understanding if one is unable to "provide good reasons for the representation that underlies her understanding" (Baumberger et al. 2017, p. 6). This parallels the justification condition for knowledge. Finally, it seems that an individual lacks proper understanding if their representation does not fit the facts: one who misrepresents the world fails to understand it. Thus, understanding seems to require a truth condition (Baumberger et al. 2017, p. 6).

These ideas are not uncontroversial. In recent work, each of these conditions has been denied as necessary for understanding. Whether or not understanding requires belief, justification, or truth is an important issue in epistemology. If reductionism is true and if knowledge requires belief, justification, and truth, then it immediately follows that one cannot have understanding without each of these conditions. However, if it could be shown that belief, justification, or truth is not necessary for understanding, this would entail that understanding is not a species of knowledge. I will briefly consider each of these issues below.

\section{Belief and Understanding}

It is widely accepted that you can only know what you believe. For example, if I do not believe that there is coffee in my cup, then I cannot know there is coffee in my cup. Is the same true for understanding?

Reductionists must think so. ${ }^{2}$ However, Wilkenfeld (2017) presents a case in which an agent seems to understand why $p$ and yet does not fully believe the explanation for why $p$. Here is the case:

Challenger: Richard is an established and skilled scientist tasked with investigating why the Challenger space shuttle exploded. His investigative instincts are excellent, and he is immediately suspicious of the O-Rings' ability to operate at cold temperatures. In fact, the reason the Challenger exploded was because of O-Ring failure. Sadly, before he goes public he is subjected to a deliberate cover-up, casting doubt on whether the O-Rings failed in this case. Arbitrarily large amounts of evidence can be presented that there really was no O-Ring failure, to the point that Richard loses confidence in his belief that the Challenger exploded because of O-Ring failure. He is now only about $30 \%$ confident that the Challenger explored because of the O-Ring failure. However, Richard still has a detailed model of how O-Ring failure would cause the explosion. Moreover, when he pictures the explosion, it is often accompanied by the fleeting suspicion that the O-

\footnotetext{
${ }^{2}$ Even some anti-reductionists claim that understanding requires belief (e.g. Kvanvig 2003; Hills 2016; Pritchard 2009).
} 
Rings might have failed. Richard is, in fact, the world's preeminent expert on the cause of the Challenger explosion-he just fails to believe his own conclusions.

According to Wilkenfeld, it seems right to say that Richard understands why the Challenger exploded even though he does not believe the correct explanation. Wilkenfeld concludes that, unlike knowledge, understanding does not require (full) belief.

But Wilkenfeld's argument can be challenged in at least two ways. First, we may question the purported intuition that Richard understands why the Challenger exploded. For example, if I were to simply ask Richard why he thinks the Challenger exploded, Richard would either say he does not understand why it exploded or he would cite an incorrect explanation for the cause of the explosion. After all, Richard is only $30 \%$ confident that the O-Rings failure was the cause of the disaster. Thus, it seems odd to say that Richard understands why the challenger exploded given that he himself would not identify the O-Ring failure as the reason why.

Second, Wilkenfeld's argument involves a sleight of hand. According to the traditional view of knowledge, belief is necessary in the sense that one cannot know that $p$ without believing that $p$. Thus, it is impossible to know that the Challenger exploded without believing that it exploded. Now consider the analogous case of understanding: to understand that (or why) $p$, one must believe that $p$. This seems uncontroversial. If Richard did not believe that the Challenger exploded, then he would not understand that (or why) it exploded. In this sense, one cannot have understanding without belief.

This illustrates that understanding requires belief in the very same way that knowledge requires belief: just as one cannot know that $p$ without believing that $p$, one also cannot understand that (or why) $p$ without believing that $p$.

There may be other types of understanding that do not require belief. For example, I can understand phlogiston theory, or astrology, or creationism without believing any of these theories. Similarly, a devout creationist may understand the theory of evolution perfectly well without believing that it describes the origins of humanity. Assuming the theory of evolution is true, we would not say that the creationist understands why humanity exists or has the features it does (Wilkenfeld 2017, p. 319). However, these are cases in which one who understands the theory still believes that the theory says 
such-and-such. Admittedly, one may understand the content of the theory without believing it; in these cases, we understand the content of a theory without believing that the theory accurately represents the world. Thus, the theory does not enable one to understand why the relevant phenomenon occurs. But if we do not believe that it accurately represents the world, then we cannot possibly understand that (or why) it accurately represents the world.

Taking another line of argument, Elgin (2004) and Dellsén (2017) say that understanding does not require belief, but rather acceptance. On L. J. Cohen's (1992) distinction, one believes that $p$ just in case one is normally disposed to feel it true that $p$ (and false that not- $p$ ) when one is attending to issues raised by $p$. By contrast, one accepts that $p$ just in case one treats it as given that $p$; that is, just in case one "adopts a policy of...including $[p]$ among one's premises for deciding what to do or think in a particular context" (Cohen 1992, p. 4). According to Dellsén (2017, p. 248), "understanding something may merely involve treating certain propositions or theories as given in the context of explaining something, as opposed to being disposed to feel that the propositions or theories are true." He provides the following case to illustrate this point:

String Theory: Carrie is a theoretical physicist in a nearby possible world (perhaps this one) in which string theory is true. Carrie has built her career around using string theory to explain various known phenomena about the natural world, and has become one of the world's leading contributors in the field because of her unmatched insight into the theory and its applications. Moreover, she has adopted the policy of treating string theory as given in her scientific endeavors - using it in explanations of various natural phenomena and thus accepts string theory for explanatory purposes. However, like many other physicists, Carrie has significant methodological reservations about string theory in its current form, and therefore is not disposed to feel that string theory is even approximately true. In other words, Carrie does not believe that string theory is even approximately true. (Dellsén 2017, p. 249)

According to Dellsén, Carrie understands the fundamental structure of her world that string theory is meant to describe. Thus, we (allegedly) have a case of understanding without belief.

However, this is not obviously a case of understanding without the relevant belief. What Carrie understands is "the fundamental structure of her world that string theory is meant to describe" (Dellsén 2017, p. 249). But what she fails to believe is something different, namely, she doesn't believe that string theory explains the fundamental structure of her world. The object of understanding has shifted, 
so the counterexample fails to establish its point. Although this is a case of understanding without belief, it is not a clear case of understanding $p$ without believing $p$. Indeed, it makes no sense to say that Carrie understands the fundamental structure of her world that string theory is meant to describe but she does not believe the fundamental structure of her world that string theory is meant to describe.

\title{
Justification and Understanding
}

It is widely assumed that knowledgeable beliefs must be arrived at in the right way; for instance, a lucky guess wouldn't suffice for knowledge, nor would a belief based on defeated evidence. In these cases, one does not have the right kind of justification for knowledge. Does understanding, like knowledge, require justification?

Hills (2016) argues that understanding differs from knowledge because only the former is compatible with defeaters that undermine one's justification. Consider the following case:

\begin{abstract}
Napoleon: Suppose that you read a history book with many details about Napoleon's career-that he was well-organized, tactically astute and ruthless, and on that basis you draw the conclusion that he was a great military leader. You are completely right and you are able to explain why he was a great leader. You can also explain why similar figures (e.g., Wellington and Marlborough) were also very good commanders. But now your history teacher, whom you regard as extremely trustworthy, tells you that Napoleon was not a great leader. Your teacher is not basing this judgement on other information or on a different interpretation of what it takes to be a great general: he simply irrationally dislikes Napoleon. You have no idea about any of this, but even so, you ignore your teacher and continue to maintain your conclusion. (Hills 2016, p. 672)
\end{abstract}

In this case, Hills says that you understand why Napoleon was a great general. Your beliefs are correct and you seem to possess the abilities required for understanding; thus, you do understand why Napoleon was a great general. However, it seems incorrect to say that you know why he was a great general-at least according to the standard account of knowledge. You have evidence that your conclusion is false, which undermines your justification. Although you choose to ignore the evidence, it nonetheless defeats your justification because it is based on seemingly reliable testimony. Thus, you cannot know that (or why) Napoleon was a great general, even though you understand why he was. This allegedly shows that understanding does not require justification, or at least the same level of justification as knowledge. 
Hills assumes that we will agree with her that this is a case of understanding without knowledge (or justification). She writes, "it is natural to say that you understand why Napoleon was a great general in these examples" and "you plainly do not know ... why Napoleon was a great general" $(2016$, p. 672$)$. I wonder whether others will feel the pull of Hill's intuitive judgment. For what it's worth, I do not. Indeed, it also seems natural to say that you cannot possibly understand why Napoleon was a great general if you do not know that (or why) he was. As Hills herself acknowledges, any sentence of the form "You understand why p but you do not know why p" sounds wrong $(2016$, p. 677). To avoid this objection, she says our intuitions about this case ought to be explained away. However, we may instead explain away the intuitions that drive Hills to claim that understanding is possible in the absence of knowledge. Perhaps it makes more sense to say that you think you understand why Napoleon was a great general, while genuine understanding is not compatible with denying contrary evidence from an "extremely trustworthy" source of relevant information. Ultimately, one wonders how much stock we should put in these intuitions. Nevertheless, Hills's argument is important because it illustrates that understanding may be irreducible to knowledge, in which case the traditional view of understanding in the philosophy of science is mistaken.

Finnur Dellsén (2017) also attempts to drive a wedge between understanding and justification by using thought experiments. He provides the following hypothetical case in which an agent allegedly grasps the explanatory relations required for understanding and yet fails to have justification:

Geometry: Alice is a struggling middle-school student who is yet to find her true academic calling. Having failed miserably at every school assignment this year, Alice now encounters geometry for the first time in her life. Unbeknownst to her, Alice has an innate knack for geometry and therefore (rather impressively) succeeds in deriving the Pythagorean theorem using a version of Pythagoras's original proof without consulting any teacher or textbook. However, from Alice's point of view, her proof of the Pythagorean theorem is no different than her previous attempts at understanding new subject matters in school this year (all of which were failures). So Alice has good reasons to believe that this attempt at understanding a new subject matter in school is a failure as well as all past attempts this year, and thus she is not justified in believing that the Pythagorean theorem is true (or that the proof is correct). (Dellsén 2017, p. 242)

According to Dellsén, "Alice clearly understands the Pythagorean theorem" (2017, p. 243) despite lacking justification. 
We may doubt this claim for a number of reasons. First, we may simply doubt that Alice believes that she has derived the Pythagorean theorem. After all, she is aware that her proof "is no different than her previous attempts at understanding new subject matters in school this year (all of which were failures)." Why, then, would she believe that her attempt was successful? Alice may lack understanding simply because she lacks the relevant belief. In reply, Dellsén says we may "suppose that Alice irrationally forms this belief in spite of her being aware of her dreadful track record" (2017, p. 242n8). But if her belief is so irrational, then we may begin to wonder whether she really has understanding (rather than just lucky true belief). Elsewhere, Dellsén says "we could easily stipulate that Alice, for whatever reason, got lucky in her attempt to prove the Pythagorean theorem and that she fails to construct similar proofs in geometry on other occasions" (2017, p. 243n10). If this is true, we might doubt that Alice exhibits understanding rather than lucky true belief.

Setting this point aside, we may also argue that Alice does have the relevant justification. Alice is able to derive the Pythagorean theorem using a version of Pythagoras's original proof because she grasps the correct mathematical relations between the theorem and other geometrical facts. Had she not grasped these relations, she would lack understanding. But the very fact that she grasps these relations is what justifies her beliefs about the proof she derives. It is the very fact that she grasps these relations-not the fact that she grasps that she grasps them-that justifies her belief. ${ }^{3}$ Although Alice's awareness of her bad track record may undermine her justification to believe that she grasps the correct relations, it needn't defeat her justification for understanding the Pythagorean theorem.

This does not conclusively show that understanding requires justification or that understanding is reducible to knowledge. ${ }^{4}$ However, I have attempted to illustrate that some common arguments against the necessity of justification for understanding misfire.

\section{Lucky Understanding}

It is commonly held that knowledge is incompatible with certain types of luck. For example, if you come to believe that it's $2 \mathrm{pm}$ on the basis of a clock that (unbeknownst to you) has stopped 12 hours ago,

\footnotetext{
${ }^{3}$ Kvanvig (2003, pp. 193-202) makes this point.

${ }^{4}$ That said, a number of anti-reductionists also claim that understanding requires justification; for example, Kvanvig (2003, $p$.

202), Elgin (2009, p. 323), and Pritchard (2009, p. 33).
} 
then you may truly and justifiably believe that it is $2 \mathrm{pm}$ even though you do not know this (Russell 1948; Gettier 1963). Your belief is just too lucky to qualify as knowledge.

Is understanding also incompatible with luck? Many epistemologists have sought to distinguish knowing from understanding by arguing that understanding is compatible with certain forms of knowledgeundermining luck. In particular, understanding is often said to be compatible with "environmental luck." Environmental luck occurs when a true belief is acquired in an epistemically unfavorable environment in which one could easily have arrived at false beliefs. ${ }^{5}$ Consider the following scenario:

Orwellian State. Winston is living in an Orwellian state in which the government attempts to falsify the past. Winston is in a room full of elaborately falsified history books, but he luckily picks up the one accurate book that was not destroyed. As he reads the book, he comes to believe many of its true claims about the past. To focus on one claim in particular, suppose Winston comes to believe that the Comanche dominated the southern plains of North America during the eighteenth century because of their superior horsemanship. ${ }^{6}$

Let's suppose that Winston grasps this explanation, it makes sense to him, and so forth. Does he now understand why the Comanche dominated the southern plains during this period? According to Kvanvig (2003), Pritchard (2009), and Hills (2016), it seems that Winston does have understanding. ${ }^{7}$ After all, Winston can now correctly answer a wide range of questions about the Comanche dominance, he grasps the relevant connections, and so on.

But does Winston also know why the Comanche dominated the southern plains? Many scholars are tempted to say that he does not. Winston's beliefs might easily have been mistaken, and one of the main lessons from the literature on epistemic luck is that knowledge requires a more secure connection to the truth: it requires a non-accidental connection between mind and world.

\footnotetext{
${ }^{5}$ This type of luck is often distinguished from "intervening luck" (or "Gettier luck") in which a person has true beliefs only due to a lucky intervention "between" the facts and her cognitive abilities (see Pritchard 2010, p. 36). Zagzebski (2001), Kvanvig (2003), and Hills (2016) claim that understanding (but not knowledge) is compatible with both types of luck. In contrast, Pritchard argues that understanding is only compatible with environmental luck. I will set aside intervening luck because the intuitions driving this debate are even more controversial than the intuitions about environmental luck. This point is acknowledged by both proponents (Hills 2016, p. 672) and critics (Pritchard 2010) of the view that understanding is compatible with intervening luck.

${ }^{6}$ This example is from Grimm (2014).

${ }^{7}$ Zagzebski (2001), Morris (2012), Rohwer (2014), and Riaz (2015) have also taken this line of argument.
} 
Hills (2016, p. 672) describes similar cases of epistemic luck:

Inaccurate Textbooks. Your history class has all been given very inaccurate textbooks, except for you. You read in your textbook some details about Napoleon's career: that he was well-organized, tactically astute and ruthless, and on that basis you draw the conclusion that he was a great military leader. You are completely right and you are able to explain why he was a great leader. And you can explain why similar figures (Wellington and Marlborough for instance) were also very good commanders.

According to Hills, this example shows that you do understand why Napoleon was a successful leader, although you do not know this fact. Kvanvig (2003, pp. 197-8) and Pritchard (2010, p. 79) describe similar examples that are designed to show that knowledge is not necessary for understanding.

Although these examples are just philosophical fictions, they illustrate an important point. Our informational environments are increasingly polluted with fake news, liars, and bullshitters. We live in what we might call epistemically hostile environments. Consequently, it is important to determine the relationship between knowledge, understanding, and environmental luck. If people like Kvanvig, Pritchard, and Hills are correct, then epistemically hostile environments may threaten our knowledge without threatening our understanding. This is rather good news. Although it may become harder to know things in our post-truth era of misinformation, we may still achieve understanding as long as we hit upon accurate sources of information.

However, it is unclear whether we can distinguish knowing from understanding by appealing to epistemic luck. In particular, the claim that knowledge (but not understanding) is incompatible with environmental luck is highly questionable. Our intuitions about cases with the same structure are flimsy, as illustrated by Hawthorne (2003), Gendler and Hawthorne (2005), and Sliwa (2015). We can easily construct cases of environmental luck where it is intuitive to ascribe knowledge. For example, Hawthorne (2003, p. 68-9) describes a scenario in which six children are given books where only one of these books provides accurate information about the capital of Austria. When asked "Which one of the schoolchildren knows the capital of Austria?", an onlooker who has witnessed the sequence of events will answer by selecting the child whose book read "Vienna" - even though that child was only given the correct answer by luck. This illustrates that knowledge, like understanding, is achievable in epistemically hostile environments, as long as the source of information is good. 
Further, Grimm (2006) puts forward some cases against the claim that understanding can be lucky, and then argues that the cases where understanding isn't undermined by luck are also cases where epistemic luck does not undermine knowledge. He therefore provides an intuitive case that knowledge and understanding seem to "sway together," at least when the details of these cases are adequately spelled out. ${ }^{8}$

Beyond the intuitive arguments for this view, there is empirical evidence that understanding and knowledge are both compatible with environmental luck. Wilkenfeld, Plunkett, and Lombrozo (2018) experimentally tested a number of different cases involving epistemic luck and they found no evidence that judgments concerning knowledge and understanding diverge as a result of a belief's etiology. ${ }^{9}$ They write, "attributions of knowledge and attributions of understanding involve comparable (and minimal) roles for epistemic luck" (Wilkenfeld et al. 2018, p. 24). This throws into doubt a crucial assumption made by scholars who claim that knowledge is incompatible with environmental luck.

Colaço et al. (2014) provide additional support for the view that knowledge and understanding are equally insensitive to epistemic luck. They designed a study to determine whether members of the

\footnotetext{
${ }^{8}$ Brogaard (2005), Khalifa (2013a), and Greco (2014) also argue that understanding is incompatible with the same type of epistemic luck as knowledge. In defense of lucky understanding, Morris (2012) claims the intuitions that rule against lucky understanding can be explained away. However, Sliwa (2015, pp. 60-61) argues that sentences of the form "I understand why $x$, but I don't know why $x^{\prime \prime}$ are infelicitous, and there is no obvious way to explain their infelicity by appealing to pragmatic considerations.

${ }^{9}$ Here's a summary of one of their experiments:

Participants were randomly assigned to read one of four vignettes, all variations on the case of Becky in the blacksmith's shop from Grimm (2006). In each vignette, Becky sees John, a blacksmith, strike a chestnut with a hammer, and sees the chestnut explode. Unbeknownst to Becky, the anvil is hot enough to cause chestnuts to explode and John is playing a game of timing his blows based on when the heat would cause each chestnut on his anvil to explode. In all vignettes, Becky forms the belief that the chestnut exploded because it was hit by the hammer ... In the normal belief condition, Becky's belief is true. John usually strikes the chestnut just before it would explode from the heat, and he does so as she is watching. In the false belief condition, John times his blows so that he strikes after each chestnut explodes due to the heat, and he does this as she is watching. Accordingly, Becky's belief that the chestnut exploded due to the hammer is false. The lucky environment condition follows Grimm's blacksmith example most closely: John usually strikes each chestnut after it explodes due to the heat. But, on the one occasion Becky is watching, his timing is off and his hammer blow does cause the chestnut to explode. Thus, Becky's belief is true, but lucky in that she would have formed a false belief based on identical evidence if she had walked in a moment earlier or later. Finally, in the veridical hallucination condition, John usually strikes the chestnut before it explodes due to the heat, and does so as Becky is watching. In this scenario though, Becky accidentally ingests a hallucinogenic plant before entering John's shop. Becky's hallucinations just happen to correspond exactly to what she would have seen if she had not been hallucinating ... After reading one of these four vignettes, participants were randomly assigned to judge either Becky's knowledge or her understanding." (Wilkenfeld et al. 2018, pp. 32-5).
}

Wilkenfeld and colleagues found no significant differences in participants' ratings of Becky's knowledge and of her understanding in any of the four conditions. 
general public will deny knowledge to the protagonist in fake barn cases of environmental luck (see Goldman 1976). Contrary to philosophical lore, Colaço and colleagues find that participants are willing to attribute knowledge in fake-barn cases, thereby undercutting the widespread assumption that environmental luck is incompatible with knowledge. Many philosophers have likewise claimed that fake barn scenarios are compatible with knowledge; e.g., Millikan (1984), Brogaard (2005), Grimm (2006, p. 529) Lycan (2006, p. 158), and Turri $(2011$, p. 8). Thus, it seems that the fake barn intuition is not "clearly enough correct for it to be usable as the premise of a good argument" (DeRose 2009, p. 49).

This casts doubt on the putative case for understanding's immunity to epistemic luck. Although one of the most common ways to argue that understanding is different from knowing is to claim that understanding is immune to the kind(s) of epistemic luck that undermine knowledge, it seems that people do not differentiate between knowing and understanding on the basis of luck.

\section{Truth and Understanding}

What is the relationship between understanding and the facts? This is one of the most hotly debated questions in the epistemology of understanding. It is widely accepted that knowledge is "factive" in the sense that a belief amounts to knowledge only if the belief is true. After all, you cannot know that the Titanic sank in 1912 if it didn't sink in 1912. But the relationship between understanding and truth is more complicated.

On the one hand, it seems clear that understanding must somehow answer to the facts. You cannot understand how the Titanic capsized if your beliefs about how it capsized are false. On the other hand, a strictly factive conception of understanding may be unable to do justice to the cognitive contributions of science. As Elgin (2017) and de Regt (2017) argue, scientists commonly rely on models, idealizations, and thought experiments that are known not to be true. For example, scientists purport to understand the behavior of actual gases by reference to so-called ideal gas, even though there is no such gas. Elgin calls these "felicitous falsehoods" and claims they are often essential to fostering understanding. ${ }^{10}$

\footnotetext{
${ }^{10}$ Philosophers are deeply divided over the connection between understanding and the facts. Opponents of factivity include Zagzebski (2001), Elgin (2007, 2009, 2017), and Riggs (2009). In contrast, Lipton (2004, 2009), Grimm (2006, 2010), Pritchard (2009, 2010), Strevens (2013), Greco (2014), Hills (2016), Frigg and Nguyen (forthcoming), Le Bihan (forthcoming), and Nawar (forthcoming) claim that understanding is factive. Insofar as one thinks that understanding reduces to knowledge, one must think that understanding is factive. If understanding is not factive, then it cannot reduce to knowledge.
} 
Taking a middle path, Kvanvig (2003) maintains that understanding is compatible with some peripheral beliefs that are false, while beliefs that are central to one's understanding must be true. On this view, false beliefs will always detract from one's understanding: our cognitive situation would improve by removing falsehoods from our belief set. This is the "quasi-factive" view of understanding.

It might seem plausible that explanations and theories must at least be approximately true to provide understanding. However, Elgin (2017) argues that scientific models involving highly unrealistic idealizations can enhance understanding. Further, it seems possible to use fictions and counterfactual scenarios to advance understanding. Consider Thomas Hobbes's genealogical account of the political sovereign. Hobbes imagines a "state of nature" in which there was no government, no laws, no civilization, but rather a war of "all against all" where life was "nasty, brutish, and short." Even though this is philosophical fantasy, it is used to shed light on the legitimacy of political authority. We could make similar points about Hume's genealogy of justice and Rawls's thought experiment involving humans in the "original position" behind a veil of ignorance (see Elgin 2017, p. 29). These theorists were under no illusions that their accounts were accurate descriptions of human history. Yet these theories are intended to foster genuine understanding nonetheless.

This illustrates that even central falsehoods are sometimes compatible with understanding. As Elgin writes,

A central element in a second grader's view of human descent may be that humans descended from apes, although, on a more sophisticated account, humans and great apes descended from a common hominid ancestor who was not, strictly speaking, an ape. Nonetheless, the child's view displays some understanding and is certainly better than thinking that humans and apes are not relatives of any sort. Likewise, even though Copernicus thought that the Earth orbits around the sun in a circle (and not in an ellipse), his theory constitutes a major advance in understanding the motion of the planets if compared to Ptolemaic theories. (2007, pp. 37-8)

This seems to contradict Kvanvig's claim that we cannot understand a subject matter unless all of the central propositions in a comprehensive body of information are true. In some cases, divergences from the truth may be large without undermining one's understanding. Indeed, Elgin says that divergences from the truth are often essential to fostering understanding. 
It seems clear that falsehoods can produce understanding. Elgin (2017), Strevens (2017), de Regt and Gijsbers (2017), and de Regt (2017) argue that divergences from the truth often foster understanding in science. Recall the case of the child who believes that human beings descended from apes. Elgin writes,

the pattern exhibited in this case is endemic to scientific education. We typically begin with rough characterizations that properly orient us toward the phenomenon, and then refine the characterizations as our understanding of the science advances. Think of the trajectory from naïve folk physics through Newtonian mechanics to relativity and quantum mechanics. (2009, p. 325)

In a similar vein, Strevens says: "many explanatory models contain idealizations, that is, deliberate falsifications that are generally considered not to harm and even to help their users to understand why certain phenomena occur" (2017, p. 37). Even theories that are utterly false may be used to understand something. Thus, deliberate falsehoods clearly play a role in helping scientists better understand the world.

It seems plausible that felicitous falsehoods may be effective routes to understanding. A simplified model may even foster better understanding than an explanatory model that contains no falsehoods. But this idea is perfectly compatible with the factive view of understanding. To say that felicitous falsehoods can yield understanding is a claim about the route to understanding; it is not a claim about what is understood (i.e., the object of understanding). A false theory may foster genuine understanding, but the phenomenon that is understood (or the predictions that one is attempting to make) must still be true-or at least approximately true. For example, the ideal gas law represents gas molecules as perfectly elastic spheres that occupy negligible space and exhibit no mutual attraction. No such gas exists, but this idealization is useful for scientific explanation and prediction. It gives accurate predictions regarding the behavior of the target systems under certain conditions (Mizrahi 2012, p. 242). But the scientists working with the ideal gas law or other idealizations do not necessarily have false beliefs as a result. The underlying idea is that idealizations can be an efficacious way to get to further truths or make true predictions.

Thus, the effectiveness of false models or idealizations is no objection to the factive view of understanding. As Kelp (2017) points out, "it is simply not part of the [factive] view that a proposition or theory can contribute to our understanding of various scientific phenomena only if it is known to be 
literally true." Fidelity to the truth does not imply that explanations adducing idealizations are epistemically unacceptable.

We may also grant that false theories can be understood. In this fairly trivial sense, understanding is compatible with falsehood. But false theories are themselves comprised of truths, just as fictional worlds are teeming with facts. It is a fact that Hamlet was the Prince of Denmark in Shakespeare's play, just as it is a fact that Geminis and Libras are a great romantic match according to astrology. Thus, understanding false theories still requires a commitment to the truth. To understand a false theory we must understand what is true of the theory.

Must the factivists claim that science is cognitively defective insofar as it relies on laws, models, and idealizations that diverge from the truth? It would be mistaken to saddle the defenders of factivity with this view (although Elgin 2004, p. 113 attributes it to them). To say that truth is mandatory for understanding is not to imply that our best science "turns out to be intellectually dishonest" (Elgin 2004, p. 113). Factivists needn't regard felicitous falsehoods as defects. Rather, they can acknowledge that felicitous falsehoods are critical to, and indeed constitutive of, the understanding delivered by science. For example, felicitous falsehoods may allow us to achieve more understanding in cases where the vastly more complicated truth would impede understanding. The point, however, is that these falsehoods are preferable to truth owing to our cognitive limitations.

In other words, the examples adduced by the non-factivists show that felicitous falsehoods are instrumentally valuable. ${ }^{11}$ Specifically, they are instrumentally valuable for cognitively limited creatures like us. It is because of our cognitive limitations that we are sometimes better off with simplified models, idealizations, and approximations. These will figure ineliminably in the success of science and thus are not defects. Indeed, they may be practically necessary. But from a purely epistemic point of view, when we bracket our cognitive shortcomings, the factivist may be right that our understanding of the world would be enhanced if it contained only truths. Our predicament is that, from the perspective of nonideal inquirers, the demand for nothing but the truth may obstruct our epistemic goals.

\footnotetext{
${ }^{11}$ Le Bihan (forthcoming) makes a similar point.
} 


\section{Understanding, Grasping, and Ability}

As mentioned earlier, a prominent view in the philosophy of science is that understanding is simply knowledge of causes. ${ }^{12}$ According to Pritchard (2010) and Hills (2016), however, there are some cases in which it is intuitive to say that one has knowledge without the corresponding understanding. Consider the following example:

Suppose that I understand why my house burned down, know why it burned down, and also know that it burned down because of faulty wiring. Imagine further that my young son asks me why his house burned down and I tell him. He has no conception of how faulty wiring might cause a fire, so we could hardly imagine that merely knowing this much suffices to afford him understanding of why his house burned down. Nevertheless, he surely does know that his house burned down because of faulty wiring, and thus also knows why his house burned down. (Pritchard 2010, p. 81)

If Pritchard is correct about this case, it illustrates that one can have knowledge without the corresponding understanding. Hills provides a similar example:

Suppose that you know why giving money to charity is right, namely because we owe assistance to the very needy. You were told this by your parents. You understand what the statement means. You believe it and it is true. You have formed it in the right way to have knowledge (by testimony from sources you rightly believe to be reliable). But you won't necessarily yet have the abilities to make accurate judgments about other, similar cases - where you are aware that your sacrifice would be more significant, or that the needs you could meet are not pressing. And so on. So you can have knowledge why without cognitive control, and so without understanding why. (Hills 2016, p. 669)

In both of these cases, understanding why something is the case seems to demand more cognitive ability than knowing why it is the case. ${ }^{13}$ In particular, understanding seems to require more than simply knowing the cause of $\mathrm{p}$ or the reason why $\mathrm{p} .{ }^{14}$ For this reason, it is widely assumed that understanding is a greater cognitive achievement than knowledge.

\footnotetext{
${ }^{12}$ We may use the term 'cause' broadly to include not just causes relations but dependency relations more broadly (see Kim 1994; Greco 2014; Grimm 2014).

${ }^{13}$ See Sliwa (2015) for a contrary view.

${ }^{14}$ Grimm (2014) disagrees with Pritchard's claim that the child knows why his house burned down.
} 
These examples may correctly show that understanding-why is not a form a knowing-why, but they do not illustrate that understanding-why is irreducible to knowledge. As Grimm (2014) argues, understanding may be a form of non-propositional knowledge of causes. This is compatible with Pritchard's and Hill's claim that understanding is not reducible to propositional knowledge-why. One might instead think of understanding as a kind of ability or know-how (that is not reducible to propositional knowledge). Thus, the argument by Pritchard and Hills is too narrow to establish the broader conclusion that understanding is irreducible to any type of knowledge. At best, it shows that one type of understanding is not reducible to one type of knowledge.

Let's suppose that understanding requires more cognitive ability than the corresponding knowledge. What precisely is required? A widely accepted view if that some kind of grasping is additionally necessary for understanding (Kitcher 1989; Kvanvig 2003; Riggs 2003; de Regt and Dieks 2005; Greco 2014; Kelp 2015; Grimm 2006, 2016; de Regt 2009; Newman 2012; Khalifa 2013a; Hills 2016; Elgin 2007; 2017; and Strevens 2017). Elgin says, "understanding the Athenian victory involved more than knowing the various truths that belong to a suitable tethered comprehensive, coherent account of the matter. The understander must also grasp how the various truths are related to each other and to other elements of the account" (2017, p. 46). Similarly, Grimm maintains that understanding involves grasping a "structure" (2016, p. 12). Hills says that understanding why p requires a grasp of the reason why $p$ (2016, p. 663). According to Baumberger and Brun (2017), a person S understands a subject matter M by means of a theory $\mathrm{T}$ to the degree that: (a) S grasps $\mathrm{T}$; (b) $\mathrm{S}$ is committed to $\mathrm{T}$; (c) $\mathrm{T}$ answers to the facts; and (d) T of M is justified for S. This view is structurally similar to the traditional view of knowledge, but it also includes a grasping condition that is absent in the case of knowledge.

We can draw out two general ideas from these various views. First, we can see that understanding, unlike knowledge, is not primarily concerned with a belief in an individual proposition. Rather, it is focused on what Boyd (forthcoming) calls "a mental representation of a relational structure." ${ }^{15}$ Second, we can see it is widely accepted that understanding requires grasping.

Precisely what "grasping" consists in is a matter of debate. Theorists have tended to use the term in an intuitive and largely metaphorical way; for instance, when one "sees" how various bits of information

\footnotetext{
${ }^{15}$ Hills (2016) argues that understanding is ultimately concerned with relationships between propositions, whereas Grimm (2014) argues that grasping is a non-propositional way of knowing. I will leave open whether a relational structure can be expressed in terms of propositions.
} 
"hang together." A natural idea is that grasping is related to coherence theories of justification (see Elgin 2004, 2006, 2007; Kvanvig 2003, 2009; Riggs 2009; Carter and Gordon 2014). Kvanvig characterizes the central feature of understanding as "in the neighborhood of what internalist coherence theories say about justification. Understanding requires the grasping of explanatory and other coherence-making relationships in a large and comprehensive body of information" (2003, p. 192). Likewise, Riggs suggests that understanding "requires a deep appreciation, grasp or awareness of how [the subject matter's] parts fit together [and] what role each one plays in the context of the whole" $\left(2003\right.$, p. 217). ${ }^{16}$

Other scholars defend an ability-based account of grasping. Elgin says, "to grasp a proposition or an account is at least in part to know-how to wield it to further one's epistemic ends" (2017, p. 33). Grimm $(2006 ; 2012 ; 2014)$ defends the view that to have understanding is to have a set of abilities or know-how needed to answer "what if things were different" questions. Khalifa (2013a) maintains that grasping involves the ability to reliably evaluate explanations. According to Hills (2016), grasping a relationship between two propositions requires "cognitive control," which is a set of abilities or know-how. These abilities include: following some explanation of why $p$ given by someone else; giving an explanation of why $p$ in your own words; and drawing the conclusion that $p$ (or that probably $p$ ) from the information that q (Hills 2016, p. 663). The idea here is that grasping a proposition is a matter of being able to use the information in some way, to have it under you control, and to be able to manipulate it. ${ }^{17}$

Although it is widely accepted that understanding requires grasping, there is no consensus about what such grasping amounts to. ${ }^{18}$ Strevens even claims that "To give a philosophical account of grasping would be an extraordinary thing," and he makes no attempt to do so. However, he does say that "to grasp a fact is like knowing a fact, but it involves a more intimate epistemic acquaintance with the state of affairs in question" (2017, p. 41).

However, we may wonder whether grasping is really anything other than simply knowing. When one "grasps" a correct explanation for why an event occurs, perhaps one simply knows the correct

\footnotetext{
${ }^{16}$ Khalifa (2017) denies that coherence is part of the core conception of understanding.

${ }^{17}$ Zagzebski (2001), Kvanvig (2003), de Regt and Dieks (2005) and Newman (2014) also connect understanding to abilities. Sullivan (2018) argues that the abilities constitutive of understanding are the same kind of cognitive abilities that we find in ordinary cases of knowledge-that (and not the kind of practical abilities associated with know-how). Thus, anti-reductionists cannot maintain that understanding is irreducible to knowledge-that by appealing to the idea that understanding requires know-how.

${ }^{18}$ See Kelp (2015) for an overview of how grasping-related conditions on understanding should be explicated.
} 
explanation. This is perfectly compatible with the view, defended by Kvanvig (2003) and Elgin (2017), that understanding involves more than knowing the various truths that belong to a comprehensive, coherent account of some topic. It may also require that we "grasp" how these various truths relate to each other; but this grasping may simply bottom out at knowing the various causal relata. Along this line, Riaz (2015) argues that grasping is not a distinct psychological state that accompanies understanding. To understand why something is the case is to grasp or "see" why it is the case, but grasping and seeing are just ways of knowing. For those tempted by this line of thought, we could simply jettison talk of "grasping" and give an account of understanding in terms of knowing. ${ }^{19}$

\section{Varieties of Understanding}

For the most part, the current debates in epistemology have not so much centered around proposals for a complete theory of understanding but rather on a variety of hotly debated questions, such as whether understanding requires belief, justification, or truth, as well as whether it is compatible with certain forms of epistemic luck. ${ }^{20}$ But we might wonder: are there any characteristics of understanding that are widely accepted? Can we say anything about the nature of understanding in general?

As Le Bihan (2017, p. 123) observes, understanding is commonly taken to: (a) involve something like grasping connections, (b) be a cognitive achievement due to ability, (c) come in degrees, ${ }^{21}$ (d) manifest itself through some abilities or know-how (i.e., to infer, generalize, or answer "what if things had been different" questions), and (e) be not easily transmittable by testimony alone. Bengson also provides a comprehensive characterization of understanding:

To genuinely understand something is to grasp it . . in such a way that it makes sense to you ... it involves genuinely grasping some portion of reality, and not simply enjoying a subjective sense of grasping it ... it displays coherence . . . it can be or become better, greater, deeper . . . it is a praiseworthy good. (2017, p. 19)

\footnotetext{
${ }^{19}$ Lynch (2019) thinks we should eschew talk of "grasping."

${ }^{20}$ Additional questions I do not have space to discuss include the relationship between knowledge, understanding, and testimony (see Hills 2009; Sliwa 2015; Hills 2016; Boyd 2017; Malfatti 2019; Croce, forthcoming), as well as the transparency of understanding (see Zagzebski 2001; Trout 2002; Pritchard 2010; Hills 2016; Grimm 2017).

${ }^{21} \mathrm{~A}$ few theorists have attempted to distinguish knowledge from understanding on the grounds that understanding, but not knowledge, comes in degrees. Although it is widely agreed that understanding comes in degrees (see Hills 2016: 665), there is some disagreement over whether knowledge admits of degrees. Kvanvig (2003) and Hills $(2016 ; 2017)$ argue that propositional knowledge does not admit of degrees, whereas Hetherington (2001) says knowledge-that is also gradable. Brogaard (2005) and Riaz (2015) argue that knowledge-why is gradable.
} 
As Bengson admits, this is not a theory of understanding but rather a theory-neutral description of the core features of understanding.

In contrast, Trout (2017) is deeply skeptical that there could be any general characterization of understanding as such. He writes,

'Understanding' may denote an unprincipled stew of states, processes, capacities, and goals that are only occasionally present when philosophers, and ordinary folks, apply the term or concept. A unified account of understanding might be valuable, but understanding isn't a natural kind or defined by a set of necessary and sufficient conditions. Any unity we find in understanding comes not from the involvement of common mechanisms across diverse cases, but rather of messy cognitive activities in the common goal of pursuing the truth. $(2017$, p. 232)

Trout goes on to say that work on the nature of understanding is "half baked" and "in a terrible state" because scholars are unable to agree on even the most basic features of understanding. As my review of the literature has shown, scholars disagree about whether understanding requires truth, whether it is reducible to knowledge, whether it is compatible with luck, whether it is propositional or nonpropositional, and whether it requires grasping.

A more fruitful approach, then, is to treat understanding not as a unified or monolithic thing, but instead to expand the senses of "understanding" to include a variety of types. Many existing analyses have done exactly this; in particular, it is now common to distinguish between understanding why, understanding how, understanding of, and understanding that-perhaps among other types of understanding. This may make the investigation of the nature and value of understanding more tractable. Instead of trying to find consensus about the nature of understanding per se, it may be better to ask what types of understanding there are.

In the recent philosophical literature, it is common to find three distinct senses of 'understanding': holistic understanding, explanatory understanding, and practical understanding.

Holistic understanding is the kind of understanding that one has toward a subject matter or domain. It is sometimes called "objectual" understanding (Kvanvig 2003, p. 191). This type of understanding is usually 
attributed using the verb "understands" followed directly by a noun; for example, "Irena understands American history" and "Lana understands quantum physics." Holistic understanding requires systematized knowledge of a comprehensive body of information, coherence, and a grasp of the dependency relations among the various items of information within a subject matter. Elgin (2017) and Kvanvig (2003) claim that holistic understanding is the "core" or "paradigm" conception of understanding. Further, they distinguish holistic understanding primarily from knowledge of individual or isolated propositions.

Explanatory understanding, by contrast, is the kind of understanding that one has when one understands why something is the case. For this reason, explanatory understanding is also often called "understanding why." This type of understanding is at the center of a lot of recent work in epistemology and the philosophy of science (see Baumberger et al. 2017 for an overview). Pritchard (2010), Hempel (1965), Kitcher (1989), Grimm (2008), Khalifa (2012), Strevens (2013), Hills (2016), and de Regt (2017) all focus on explanatory understanding, and Pritchard and Hills say it is the paradigmatic form of understanding.

The focus of explanatory understanding is somewhat narrower than holistic understanding. Instead of striving to understand a subject matter or domain, explanatory understanding is typically directed at a specific phenomenon or question; for instance, understanding why the earth's average temperature is rising or why the sky is blue.

Pritchard contrasts explanatory understanding with understanding-that, which he calls "propositional understanding." According to Pritchard, explanatory understanding usually isn't concerned with propositions because "it is rare to talk of understanding that $p$ " (2010, p. 74). ${ }^{22}$ However, it is plausible that understanding why $p$ requires that one's understanding be directed toward a set of propositions, namely, those reasons as to why $p$ is the case (see Hills 2016 and Boyd 2017). Thus, the contrast between explanatory understanding and propositional understanding is spurious. Pritchard's reasoning does not necessarily speak against the idea that explanatory understanding is also propositional.

For Kvanvig, the primary contrast is between holistic understanding and understanding-that. Elgin makes a similar point:

\footnotetext{
${ }^{22}$ This is actually false (see Hannon 2019, p. 231n9).
} 
There are two obvious candidates for the bearer of epistemic entitlement: individual propositions and more comprehensive bodies of information. I can say, 'I understand that the Comanches dominated the southern plains of North America in the 18th century'. Or I can say, 'I understand the power relations among the tribes in the southern plains in the 18th century'. (2009, p. 321)

Both Kvanvig and Elgin tend to contrast holistic understanding with a specific kind of propositional understanding, namely understanding-that. Elgin goes on to say, "If the primary unit of understanding is the proposition, then the difference between knowledge and understanding seems slight" (see also Gordon 2012).

These types of understanding may be further contrasted with another, more neglected form of understanding: understanding how to do something. Zagzebski (2008) call this "understanding-how" and she takes it to be the paradigmatic type of understanding. Bengson (2017) calls it "practical understanding" and contrasts it with "theoretical understanding." Recent work in epistemology and the philosophy of science has focused on theoretical understanding, where the emphasis is on whether understanding is factive, explanatory, immune to luck, and so forth. Practical understanding, however, is centrally concerned with skillful action and practical activity. As such, this type of understanding is more closely tied to abilities (i.e., physical dispositions, habits, or bodily activities) than explanations. For example, a player who understands how to catch a fly ball might be unable to explain how he can do this, and explanations seem inadequate to imbue such a skill. As any sports fan will know, it is difficult not to notice the banality of explanations given by top athletes in post-game TV interviews. Even the best athletes are often unable to describe the content of their physical prowess without availing themselves to strings of clichés like "taking it one pitch at a time" and "focusing on fundamentals." For this reason, philosophers of mind, action theory, and phenomenology have tended to focus on questions concerning the embodiment, automaticity, and (non)conceptuality of practical understanding (Bengson 2017).

The distinction between theoretical and practical understanding is probably not exhaustive. There may be other forms of understanding that do not belong to either category. To use an example from Bengson (2017, p. 24), "a psychoanalyst's empathetic understanding of a patient, or a lover's understanding of a beloved, is (perhaps) neither theoretical nor practical." In addition to empathetic understanding (see 
Hannon, forthcoming), there is moral understanding (Hills 2009), aesthetic understanding (Hills 2017), religious understanding (Ellis 2017), linguistic understanding (Longworth 2008), historical understanding (Little 2017), philosophical understanding (Graham 2017), mathematical understanding (Lipton 2011), and scientific understanding (de Regt 2017), presumably among many others. Whether or not these are all distinct kinds of understanding, as opposed to merely different domains of (the same type of) understanding, is an open question. In all likelihood, there are multiple types of understanding across different domains.

\section{Concluding Remarks}

By distinguishing these varieties of understanding, we may better appreciate the nature and value of this intellectual achievement (or these intellectual achievements). For example, it may be that some forms of understanding are more likely reducible to knowledge than others. Khalifa (2012), for instance, argues that explanatory understanding is a form a propositional knowledge, but this is compatible with the claim that other forms of understanding are not reducible to knowledge. Further, it may be that some forms of understanding are more likely to be factive, immune to luck, and so on, than others. Distinguishing various types of understanding will allow us to see which features they have in common and what, if anything, makes them different. Do they take the same objects (e.g., theories, phenomena, etc.)? Are some types more valuable than others? Can some be explicated in terms of others? We cannot make headway on these issues until we appreciate the various senses of "understanding."

Recent work in the epistemology of understanding has shed light on the nature, value, and varieties of understanding; however, a variety of topics call for more research. First, we may reasonably ask what these various senses of understanding have in common. Is there a way to unearth some unity amid this diversity? Second, what is the boundary between understanding and other epistemic states, such as knowledge, imagination, and wisdom? This question is immediately connected to a third issue, namely, epistemic value. Are some types of understanding more valuable than others? Are they instrumentally or intrinsically valuable? Does the value of understanding exceed the value of knowledge? Fourth, is understanding the goal in inquiry? According to de Regt (2017), understanding is the goal of science. Hills (2009) claims that understanding is required for an action to have moral worth. Pritchard (2010) argues that inquiry generally ought to end at understanding; while Hannon (2019) claims that ordinary inquiry ought to aim for knowledge rather than understanding. Fifth, we may connect this point about the aim of inquiry with the epistemology of education. According to many epistemologists, truth is the 
ultimate goal of inquiry. Outside of academic philosophy, however, understanding is often invoked as the primary goal of education. In general, we may wonder whether understanding is (or ought to be) the goal of some inquiries but not others. 


\section{References}

Achinstein, Peter. 1983. The Nature of Explanation (Oxford, UK: Oxford University Press).

Ammon, Sabine. 2016. "Explaining Understanding, Understanding Knowledge," in Explaining

Understanding: New Perspectives from Epistemology and Philosophy of Science, ed. Stephen Grimm, Christoph Baumberger, and Sabine Ammon (New York, NY: Routledge), pp. 92-110.

Aristotle. 1993. Posterior Analytics (Oxford, UK: Oxford University Press).

Baumberger, Christoph. 2011. "Understanding and its Relation to Knowledge," in Epistemology: Contexts, Values, Disagreement (Proceedings of the 34th International Ludwig Wittgenstein Symposium), ed. Christoph Jäger and Winfried Loeffler (Germany: Ontos Verlag), pp. 16-18.

Baumberger, Christoph, Claus Beisbart, and Georg Brun. 2017. "What is Understanding? An Overview of Recent Debates in Epistemology and Philosophy of Science," in Explaining Understanding: New Perspectives from Epistemology and Philosophy of Science, ed. Stephen Grimm, Christoph Baumberger, and Sabine Ammon (New York, NY: Routledge), pp. 1-34.

Baumberger, Christoph and Georg Brun. 2017. "Dimensions of Objectual Understanding," in Explaining Understanding: New Perspectives from Epistemology and Philosophy of Science, ed. Stephen Grimm, Christoph Baumberger, and Sabine Ammon (New York, NY: Routledge), pp. 165-189.

Bengson, John. 2017. "The Unity of Understanding," in Making Sense of the World: New Essays on the Philosophy of Understanding, ed. Stephen Grimm (New York, NY: Oxford University Press), pp. 15-50.

Boyd, Kenneth. 2017. "Testifying Understanding," Episteme, vol. 14, no. 1, pp. 103-127.

-----. Forthcoming. "Environmental Luck and the Structure of Understanding," Episteme.

Brogaard, Berit. 2005. “I Know, Therefore I Understand," Unpublished manuscript.

Carter, J. Adam, and Emma. C. Gordon. 2014. "Objectual Understanding and the Value Problem," American Philosophical Quarterly, vol. 51, no. 1, pp. 1-13.

Christian, James L. 2009. Philosophy: An Introduction to the Art of Wondering (Boston, MA: Wadsworth Cengage Learning).

Cohen, L. Jonathan. 1992. An Essay on Belief and Acceptance (Oxford, UK: Clarendon Press).

Colaco, David, Wesley Buckwalter, Stephen Stich, and Edouard Machery. 2014. "Epistemic Intuitions in Fake-barn Thought Experiments," Episteme, vol. 11, no.2, pp. 199-212.

Croce, Michel. Forthcoming. "Moral Understanding, Testimony, and Moral Exemplarity," Ethical Theory and Moral Practice.

Dellsén, Finnur. 2017. "Understanding without Justification or Belief," Ratio, vol. 30 no. 3, pp. 239-254. 
de Regt, Henk 2009. "Understanding and Scientific Explanation," in Scientific Understanding: Philosophical Perspectives, ed. Henk de Regt, Sabine Leonelli, and Kai Eiger (Pittsburgh: University of Pittsburgh Press), pp. 21-42.

----- 2015. “Scientific Understanding: Truth or Dare?" Synthese, vol. 192, no. 12, pp. 3781-3797

----- 2017. Understanding Scientific Understanding (New York, NY: Oxford University Press).

de Regt, Henk and Dennis Dieks. 2005. "A Contextual Approach to Scientific Understanding," Synthese, vol. 144 , no. 1 , pp. $137-170$.

de Regt, Henk and Victor Gijsbers. 2017. "How False Theories Can Yield Genuine Understanding," in Explaining Understanding: New Perspectives from Epistemology and Philosophy of Science, ed. Stephen Grimm, Christoph Baumberger, and Sabine Ammon (New York, NY: Routledge), pp. 50-75.

DeRose, Keith. 2009. The Case for Contextualism (Oxford, UK: Oxford University Press).

Elgin, Catherine. 2004. "True Enough," Philosophical Issues, vol. 14, no. 1, pp. 113-131.

----- 2006. "From Knowledge to Understanding," in Epistemology Futures, ed. Stephen Hetherington (Oxford, UK: Oxford University Press), pp. 199-215.

----- 2007. “Understanding and the Facts," Philosophical Studies, vol. 132, no. 1, pp. 33-42.

2009. "Is Understanding Factive?" in Epistemic Value, ed. Adrian Haddock, Alan Millar, and Duncan Pritchard (New York, NY: Oxford University Press), pp. 322-330.

----- 2017. True Enough (Cambridge, MA: MIT Press).

Ellis, Fiona. 2017. New Models of Religious Understanding (Oxford, UK: Oxford University Press).

Frigg, Roman and James Nguyen. Forthcoming. "Mirrors without Warnings," Synthese.

Gendler, Tamar and John Hawthorne. 2005. "The Real Guide to Fake Barns: A Catalogue of Gifts for Your Epistemic Enemies," Philosophical Studies, vol. 124, no. 3, pp. 331-352.

Gettier, Edmund. 1963. “Is Justified True Belief Knowledge?” Analysis vol. 23, no. 6, pp. 121-123.

Goldman, Alvin. 1976. "Discrimination and Perceptual Knowledge," Journal of Philosophy, vol. 73, no. 20, pp. 771-791.

Gordon, Emma C. 2012. "Is there Propositional Understanding?" Logos and Episteme, vol. 3, no. 2, pp. 181-192.

Graham, Gordon. 2017. "Philosophy, Knowledge, and Understanding," in Making Sense of the World: New Essays on the Philosophy of Understanding, ed. Stephen Grimm (New York, NY: Oxford University Press), pp. 99-116. 
Greco, John. 2014. "Episteme: Knowledge and Understanding," in Virtues and Their Vices, ed. Kevin Timpe and Craig Boyd (New York, NY: Oxford University Press), pp. 285-302.

Grimm, Stephen. 2006. "Is Understanding a Species of Knowledge?" British Journal for the Philosophy of Science, vol. 57, no. 3, pp. 515-535.

----- 2012. "The Value of Understanding," Philosophy Compass, vol. 7, no. 2, pp. 103-117.

----- 2014. "Understanding as Knowledge of Causes," in Virtue Epistemology Naturalized: Bridges between Virtue Epistemology and Philosophy of Science, ed. Abrol Fairweather (Dordrecht: Springer), pp. 329-346.

2016. "How Understanding People Differs from Understanding the Natural World," Philosophical Issues, vol. 26, no. 1, pp. 209-225.

----- 2017. "Understanding and Transparency," in Explaining Understanding: New Perspectives from Epistemology and Philosophy of Science, ed. Stephen Grimm, Christoph Baumberger, and Sabine Ammon (New York, NY: Routledge), pp. 212-229.

Grimm, Stephen, Christoph Baumberger, and Sabine Ammon. eds., 2017. Explaining Understanding: New Perspectives from Epistemology and Philosophy of Science (New York, NY: Routledge).

Hannon, Michael. 2019. What's the Point of Knowledge? (New York, NY: Oxford University Press).

----- Forthcoming. "Empathetic Understanding and Deliberative Democracy," Philosophy and Phenomenological Research.

Hawthorne, John. 2003. Knowledge and Lotteries (Oxford, UK: Oxford University Press).

Hempel, Carl. 1965. Aspects of Scientific Explanation and Other Essays in the Philosophy of Science (New York, NY: Free Press).

Hetherington, Stephen. 2001. Good Knowledge, Bad Knowledge: On Two Dogmas of Epistemology (Oxford, UK: Oxford University Press).

Hills, Alison. 2009. "Moral Testimony and Moral Epistemology," Ethics, vol. 120, no. 1, pp. 94-127.

2016. “Understanding Why," Noûs, vol. 49, no. 2, pp. 661-688.

----- 2017. "Aesthetic Understanding," in Making Sense of the World: New Essays on the Philosophy of Understanding, ed. Stephen Grimm (New York, NY: Oxford University Press), pp. 160-176.

Janvid, Mikael. 2012. "Knowledge versus Understanding: The Cost of Avoiding Gettier," Acta Analytica vol. 27, no. 2, pp. 183-197. 
Kelp, Christoph. 2014. "Knowledge, Understanding, and Virtue," in Virtue Epistemology Naturalized: Bridges between Virtue Epistemology and Philosophy of Science, ed. Abrol Fairweather (Dordrecht: Springer), pp. 347-360.

----- 2015. “Understanding Phenomena," Synthese, vol. 192, no. 12, pp. 3799-3816.

2017. "Towards a Knowledge-Based Account of Understanding," in Explaining Understanding: New Perspectives from Epistemology and Philosophy of Science, ed. Stephen Grimm, Christoph Baumberger, and Sabine Ammon (New York, NY: Routledge), pp. 251-271.

Khalifa, Kareem. 2011. "Understanding, Knowledge, and Scientific Antirealism," Grazer Philosophische Studien, vol. 83, no. 1, pp. 93-112.

----- 2012. “Inaugurating Understanding or Repackaging Explanation?" Philosophy of Science, vol. 79, no. 1, pp. 15-37.

----- 2013a. "Understanding, Grasping, and Luck," Episteme, vol. 10, no. 1, pp. 1-17.

------ 2013b. “Is Understanding Explanatory or Objectual?" Synthese, vol. 190, no. 6, pp. 1153-1171.

----- 2017. Understanding, Explanation, and Scientific Knowledge (Cambridge, UK: Cambridge University Press).

Kim, Jaegwon. 1994. "Explanatory Knowledge and Metaphysical Dependence," Philosophical Issues, vol. 5, pp. 51-69.

Kvanvig, Jonathan. 2003. The Nature and Value of Knowledge (Cambridge, UK: Cambridge University Press).

----- 2009. "The Value of Understanding," in Epistemic Value, ed. Duncan Pritchard, Adrian Haddock, and Alan Millar (New York, NY: Oxford University Press), pp. 95-111.

Kitcher, Philip. 1989. "Explanatory Unification and the Causal Structure of the World," in Scientific Explanation, ed. Philip Kitcher and Wesley Salmon (Minneapolis: University of Minnesota Press), pp. 410-505.

Lawler, Insa. 2016. "Reductionism about Understanding Why," Proceedings of the Aristotelian Society, vol. 116, no. 2, pp. 229-236.

Le Bihan, Soazig. 2017. "Enlightening Falsehoods: A Modal View of Scientific Understanding," in Explaining Understanding: New Perspectives from Epistemology and Philosophy of Science, ed. Stephen Grimm, Christoph Baumberger, and Sabine Ammon (New York, NY: Routledge), pp. 111-136.

----- Forthcoming. "Partial Truth versus Felicitous Falsehoods," Synthese.

Lipton, P. 2004. Inference to the Best Explanation (London: Routledge). 
----- 2009. "Understanding without Explanation," in Scientific Understanding: Philosophical Perspectives, ed. Henk de Regt, Sabine Leonelli, and Kai Eiger (Pittsburgh: University of Pittsburgh Press).

----- 2011. "Mathematical Understanding," in Meaning in Mathematics, ed. John Polkinghorne (Oxford, UK: Oxford University Press).

Little, Daniel. 2017. "Philosophy of History," in Stanford Encyclopedia of Philosophy, ed. E. N. Zalta. URL = https://plato.stanford.edu/archives/sum2017/entries/history/.

Longworth, Guy. 2008. "Linguistic Understanding and Knowledge," Noûs, vol. 42, no. 1, pp. 50-79.

Lycan, William. 2006. "On the Gettier Problem Problem," in Epistemology Futures, ed. Stephen Hetherington (Oxford, UK: Oxford University Press).

Lynch, Michael. 2019. "Understanding and Coming to Understand," in Making Sense of the World: New Essays on the Philosophy of Understanding, ed. Stephen Grimm (New York, NY: Oxford University Press), pp. 195-209.

Malfatti, Federica. 2019. “Can Testimony Generate Understanding?" Social Epistemology, vol. 33, no. 6, pp. 477-490.

Millikan, Ruth. 1984. Thought, Language, and Other Biological Categories (Cambridge, MA: MIT Press).

Mizrahi, Moti. 2012. "Idealizations and Scientific Understanding," Philosophical Studies, vol. 160, no. 2, pp. 237-252.

Morris, Kevin. 2012. "A Defense of Lucky Understanding," British Journal for the Philosophy of Science, vol. 63, no. 2, pp. 357-371.

Nawar, Tamer. Forthcoming. "Veritism Refuted? Understanding, Idealizations, and the Facts," Synthese.

Newman, Mark. 2012. "An Inferential Model of Scientific Understanding," International Studies in the Philosophy of Science, vol. 26, no. 1, pp. 1-26.

----- 2014. "EMU and inference: what the explanatory model of scientific understanding ignores," European Journal for Philosophy of Science, vol. 4, no. 1, pp. 55-74.

----- 2017. "Theoretical Understanding in Science," British Journal for the Philosophy of Science, vol. 68 no. 2, pp. 571-595.

Pritchard, Duncan. 2010. "Knowledge and Understanding," in The Nature and Value of Knowledge: Three Investigations, ed. Duncan Pritchard, Alan Millar, and Adrian Haddock (New York, NY: Oxford University Press).

2009. "Knowledge, Understanding and Epistemic Value," in Epistemology, Royal Institute of Philosophy Supplements, ed. Anthony O’Hear (Cambridge, UK: Cambridge University Press), pp. 19-43. 
Riaz, Amber. 2015. “Moral Understanding and Knowledge," Philosophical Studies, vol. 172, no. 1, pp. 113-128.

Riggs, Wayne. 2003. "Understanding 'Virtue' and the Virtue of Understanding," in Intellectual Virtue: Perspectives From Ethics and Epistemology, ed. Michael DePaul and Linda Zagzebski (Oxford, UK: Clarendon Press).

----- 2009. "Understanding, Knowledge, and the Meno Requirement," in Epistemic Value, ed. Adrian Haddock, Alan Millar, and Duncan Pritchard (New York, NY: Oxford University Press), pp. 331-338.

Rohwer, Yasha. 2014. "Lucky Understanding without Knowledge," Synthese, vol. 191, no. 5, pp. 1-15.

Russell, Bertrand. 1948. Human Knowledge: Its Scope and Limits (London, UK: George Allen and Unwin).

Salmon, Wesley. 1984. Scientific Explanation and the Causal Structure of the World (Princeton, NJ: Princeton University Press).

Sliwa, Paulina. 2015. "Understanding and Knowing," Proceedings of the Aristotelian Society, vol. 115, no. 1, pp. 57-74.

Strevens, Michael. 2013. "No Understanding without Explanation," Studies in History and Philosophy of Science, vol. 44, no. 3, pp. 510-515.

----- 2017. "How Idealizations Provide Understanding," in Explaining Understanding: New Perspectives from Epistemology and Philosophy of Science, ed. Stephen Grimm, Christoph Baumberger, and Sabine Ammon (New York, NY: Routledge), pp. 37-49.

Sullivan, Emily. 2018. "Understanding: not know-how," Philosophical Studies, vol. 175, no. 1, pp. 221240.

Trout, J. D. 2002. "Scientific Explanation and the Sense of Understanding," Philosophy of Science, vol. 69, no. 2, pp. 212-233.

----- 2017. "Understanding and Fluency," in Making Sense of the World: New Essays on the Philosophy of Understanding, ed. Stephen Grimm (New York, NY: Oxford University Press), pp. 233-251.

Turri, John. 2011. "Manifest Failure: The Gettier Problem Solved," Philosophers' Imprint, vol. 11, no. 8, pp. 1-11.

Wilkenfeld, Daniel. 2017. "Understanding without Believing," in Explaining Understanding: New Perspectives from Epistemology and Philosophy of Science, ed. Stephen Grimm, Christoph Baumberger, and Sabine Ammon (New York, NY: Routledge), pp. 318-334.

Wilkenfeld, Daniel, David Plunkett, and Tania Lombrozo. 2016. "Depth and Deference: When and Why We Attribute Understanding," Philosophical Studies, vol. 173, no. 2, pp. 373-393.

Woodward, James. 2003. Making Things Happen: A Theory of Causal Explanation (Oxford, UK: Oxford University Press). 
Zagzebski, Linda. 2001. "Recovering Understanding," in Knowledge, Truth, and Duty: Essays on Epistemic Justification, Responsibility, and Virtue, ed. Matthias Steup (Oxford, UK: Oxford University Press), pp. 235-252.

---- 2008. On Epistemology (New York, NY: Wadsworth Cengage Learning). 